\title{
Cytokine responses in primary and secondary respiratory syncytial virus infections
}

\author{
Kelechi Ugonna' ${ }^{1}$ Konstantinos Douros ${ }^{2}$, Colin D. Bingle ${ }^{3}$ and Mark L. Everard ${ }^{4}$
}

BACKGROUND: Primary respiratory syncytial virus (RSV) infections are characterized by high levels of IL-8 and an intense neutrophilia. Little is known about the cytokine responses in secondary infections. Preschool children experiencing RSV secondary infections were recruited from the siblings of infants admitted to hospital with RSV acute bronchiolitis.

METHODS: Fifty-one infants with acute bronchiolitis (39 RSV positive, 12 RSV negative) and 20 age-matched control infants were recruited. In addition, seven older siblings of infants from the RSV-positive cohort and confirmed RSV infection were recruited. Samples of nasal secretions were obtained using a flocked swab, and secretions extracted using centrifugation. Cytokine bead array was used to obtain levels of interleukin (IL)-17A, IL-8, IL-6, IL-21, and tumor necrosis factor- $\alpha$.

RESULTS: Levels of IL-8 and IL- 6 were significantly lower in the RSV-positive siblings compared with the RSV-positive infants. There were no significant differences between levels of the other cytokines in the primary and secondary infections.

CONCLUSION: The very high levels of IL-8 and IL-6 response characteristic of the primary RSV infection was not observed in secondary RSV-positive infections and this did not appear to be due to a global reduction in cytokine production.

$T$ he respiratory syncytial virus (RSV) is responsible for annual epidemics of respiratory disease affecting the whole population. Its impact is most marked in the very young with up to $2 \%$ of all infants being hospitalized with an RSV infection during their first winter (1-4). Worldwide, RSV is responsible for many millions of hospitalizations and many tens of thousands of deaths (5). The acute illness is characterized by an intense neutrophilia within the airways $(6,7)$ driven in large part by high levels of IL-8 (8) driving recruitment accompanied by prolonged survival of neutrophils (9). Neutrophil products such as myeloperoxidase and human neutrophil elastase (8) contribute significantly to mucosal inflammation leading to increased airways secretions, coughing, and sneezing. Hence, neutrophils appear to play a central role in the causation of symptoms, and it is likely that they contribute to transmission of the virus through the increased generation mucus and thus of infected aerosolized droplets.

It is also possible that neutrophils play a role in limiting viral replication and therefore contribute to clearance of the virus in humans although direct evidence for this is lacking. One study involving bovine RSV infection of calves (10) suggested that neutrophils were capable of taking up the virus. Studies utilizing highly purified RSV, in which contaminating cytokines generated during culture of the virus were removed, indicate that neutrophils do not have innate recognition and signaling systems for RSV (11), although their function is indirectly influenced by products from activated macrophages (12).

Data from studies involving other pulmonary pathogens such as Streptococcus pneumonia suggest that the release of interleukin (IL-17) from CD4 T cells (TH17) is extremely important in enhancing the ability of neutrophils to kill the organisms in the airways $(13,14)$. Hence, the generation of pathogen-specific IL-17 cells may be an important component of effective secondary responses to respiratory pathogens (15). IL-17-producing T cells are induced in primary infections through pathways that involve STAT3 and IL-6 $(16,17)$. High levels of IL-6 have been found in the airways of infants with RSV bronchiolitis $(18,19)$, and a number of studies have identified IL-17 in the airways (20-24) and plasma $(21,24)$ of infants with RSV infection. Two studies have found lower levels of IL-17 in the airways of the most severely affected infants, and the authors suggested that higher IL-17 levels were associated with protection against more severe disease $(21,24)$. Hence, it is possible that the induction of IL-17-producing lymphocytes may represent one of the mechanisms contributing to limiting RSV replication in subsequent infections.

In order to compare cytokine responses in primary and secondary RSV infections, nasal samples were obtained from infants admitted to hospital with a primary RSV infection and from preschool-aged siblings of these infants who were manifesting symptoms of an upper respiratory tract viral infection. The study design was based on the well-established observation that most infants are infected with RSV during their first

'Department of Respiratory Medicine, Sheffield Children's Hospital, Sheffield, UK; ${ }^{2}$ Third Department of Paediatrics, Attikon Hospital, University of Athens School of Medicine, Athens, Greece; ${ }^{3}$ Department of Infection and Immunity, University of Sheffield, Sheffield, UK; ${ }^{4}$ School of Paediatrics and Child Health, University of Western Australia, Princess Margaret Hospital, Subiaco, Western Australia, Australia. Correspondence: Mark L. Everard (ark.everard@uwa.edu.au)

Received 12 May 2015; accepted 30 November 2015; advance online publication 9 March 2016. doi:10.1038/pr.2016.29 
winter and that all have been infected by the end of their second winter, while re-infection with the virus is frequent throughout life, including during the preschool years (25-28). Hence, infants admitted to hospital with a severe RSV infection will be experiencing a primary infection, while their symptomatic preschool siblings with an RSV infection would be experiencing a secondary infection.

\section{RESULTS}

Table 1 contains clinically relevant data for each of the patient groups included in this study. There was no significant difference in the ages of the infants in any of the three groups.

The levels of all measured cytokines in the nasal secretions of infants with RSV bronchiolitis were elevated compared with controls. The inflammatory response in those without RSV was

Table 1. Demographics of each patient group with $95 \%$ confidence interval $(\mathrm{Cl})$ where relevant

\begin{tabular}{|c|c|c|c|c|c|c|c|c|}
\hline & & $\begin{array}{c}\text { Male: } \\
\text { female ratio }\end{array}$ & Disease & Number & $\begin{array}{l}\text { Range } \\
\text { of ages } \\
\text { (months) }\end{array}$ & $\begin{array}{l}\text { Mean age (months) } \\
(\mathrm{Cl}) \text { (corrected for } \\
\text { gestational age) }\end{array}$ & $\begin{array}{l}\text { Days from onset } \\
\text { of symptoms to } \\
\text { sample }(\mathrm{Cl})\end{array}$ & $\begin{array}{c}\text { \% requiring } \\
\text { oxygen } \\
\text { therapy }\end{array}$ \\
\hline I: infant & Control & 0.66 & None & 20 & $1-10$ & $6.3(5.44-7.26)$ & - & - \\
\hline II: infant & RSV-ve & 1.4 & Bronchiolitis $^{\mathrm{a}}$ & 12 & $0.8-11$ & $6.1(5.06-7.14)$ & $7.4(5.4-9.4)$ & 41 \\
\hline III: infant & $\begin{array}{l}\text { RSV } \\
\text { positive }\end{array}$ & 1.05 & Bronchiolitis & 39 & $0.5-12$ & $6.9(5.87-7.93)$ & $6.3(5.4-7.2)$ & 61 \\
\hline IV: older sibling of RSV-positive infant & $\begin{array}{l}\text { RSV } \\
\text { positive }\end{array}$ & 0.75 & URTI & 7 & $18-42$ & $31.2(26.8-35.6)$ & $8.3(7.18-9.42)$ & - \\
\hline
\end{tabular}

Viruses identified by PCR: adenovirus (1), metpneumovirus (2), parainfluenza (2), influenza (1), rhinovirus (2), and none (4).

Table 2. Geometric means (GM) of interleukins and their $95 \%$ confidence intervals (Cl)

\begin{tabular}{|c|c|c|c|c|c|}
\hline & $\begin{array}{c}\mathrm{IL}-17 \mathrm{~A} \\
(\mathrm{pg} / \mathrm{ml}) \mathrm{GM}(\mathrm{Cl})\end{array}$ & $\begin{array}{c}\mathrm{IL}-8 \\
(\mathrm{pg} / \mathrm{ml}) \mathrm{GM}(\mathrm{Cl})\end{array}$ & $\begin{array}{c}\text { IL-6 } \\
(\mathrm{pg} / \mathrm{ml}) \mathrm{GM}(\mathrm{Cl})\end{array}$ & $\begin{array}{c}\text { IL-21 } \\
(\mathrm{pg} / \mathrm{ml}) \mathrm{GM}(\mathrm{Cl})\end{array}$ & $\begin{array}{c}\text { TNF } \alpha \\
(\mathrm{pg} / \mathrm{ml}) \mathrm{GM}(\mathrm{Cl})\end{array}$ \\
\hline I: infant control & $8.2(7.3-9.1)$ & $41.1(21.2-79.7)$ & $3.2(2.4-4.3)$ & $49.3(44.7-54.5)$ & $3.4(3.0-3.8)$ \\
\hline II: RSV-negative infant & $12.2(8.1-18.2)$ & $239.5(69.1-855.4)$ & $6.1(2.7-13.6)$ & $56.8(42.6-75.6)$ & $5.5(3.0-10.1)$ \\
\hline III: RSV-positive infant & $15.7(11.3-21.7)$ & $509.3(306.3-846.8)$ & $19.2(10.9-33.5)$ & $72.1(58.1-89.4)$ & $7.5(2.8-13.6)$ \\
\hline IV: RSV-positive sibling & $9.2(5.7-14.8)$ & $66.7(28.1-158.6)$ & $3.27(2.3-4.6)$ & $66.1(44.2-98.9)$ & $3.1(1.9-5.2)$ \\
\hline
\end{tabular}

$P$ values refer to differences of interleukins logarithmic values in each group, detected with ANOVA.

Statistically significant differences between groups, for each interleukin:

IL-8: RSV-positive infant-infant control $(P<0.001)$; RSV-positive infant-RSV-positive sibling $(P=0.013)$, RSV-negative infant-infant control $(P=0.017)$

IL-17A: RSV-positive infant-infant control $(P=0.017)$

IL-6: RSV-positive infant-infant control $(P<0.001)$, RSV-positive infant-RSV-positive sibling $(P=0.027)$

IL-21: RSV-positive infant-infant control $(P=0.018)$

TNF $\alpha$ : RSV-positive infant-infant control $(P=0.008)$.

$\mathrm{Cl}$, confidence interval.
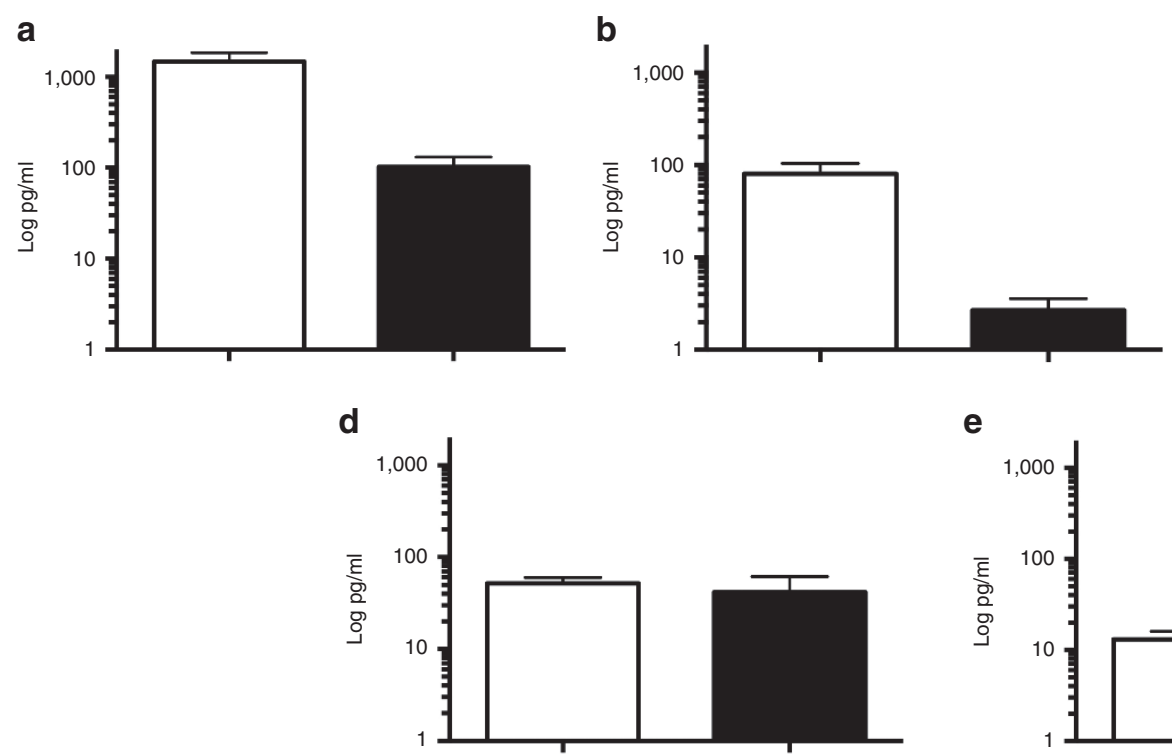
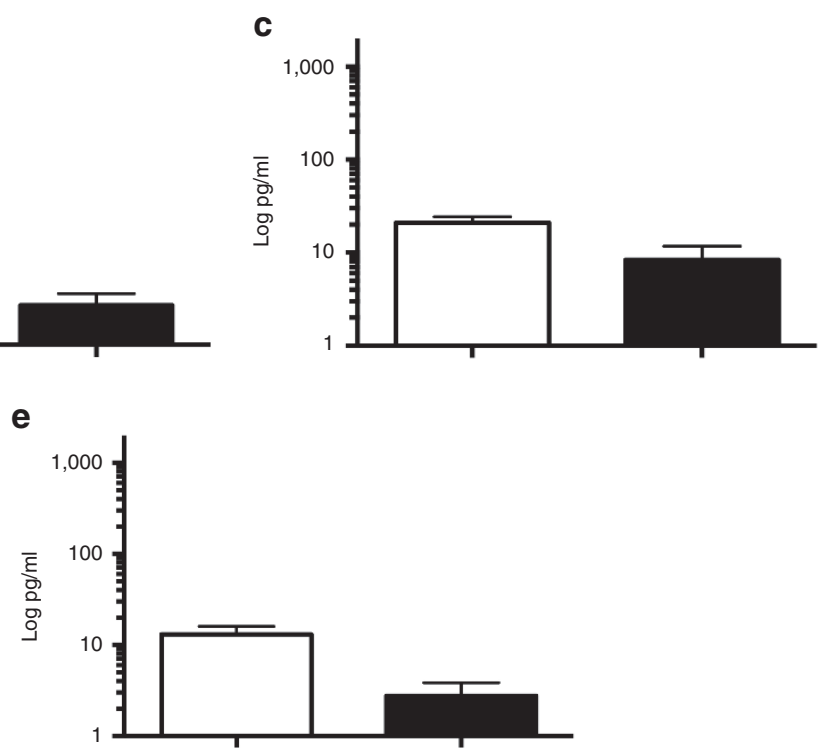

Figure 1. Cytokine levels in the nasal samples from RSV-positive infants and their older siblings (excludes infants in whom RSV infection was not confirmed in older sibling). (a) IL-8, (b) IL-6, (c) IL-17a, (d) IL-21, and (e) TNF. Blank boxes indicate RSV-positive infants, and filled boxes indicate RSV-positive siblings. 


\section{Articles | Ugonna et al.}

less intense with only the elevation of IL-8 levels reaching statistical significance when compared with control infants, while all five cytokines were significantly elevated in the RSV infant group. Levels of IL- 8 in the nasal secretions of RSV-positive infants were greater than those observed in the RSV-negative cohort (Table 2).

Data for only those RSV-positive infants who had a RSVpositive sibling and that for their siblings is presented in Figure 1. Levels of both IL-8 and IL-6 in nasal secretions from older siblings, all of whom had a clinically significant upper respiratory tract symptom, were significantly lower than those observed in their infant RSV-positive siblings. In contrast, levels of IL-17a, IL-21, and tumor necrosis factor- $\alpha$ (TNF $\alpha$ ) were not statistically different in the two groups. Consequently, the relative concentrations of the former two cytokines and later three were significantly different when comparing the two groups. The data for relative ratio of these cytokines in all four study groups is presented in Table 3.

\section{DISCUSSION}

This is the first study comparing the pattern of inflammation seen during an acute severe primary RSV infection with that observed in a secondary infection in preschool children. The results suggest that there are key differences in cytokine profiles during primary and secondary infections. Levels of IL-8 and IL- 6 were significantly lower during the secondary infections, but this was not the case for the other cytokines, suggesting significant differences in the relative contributions of these cytokines to the inflammation associated with infection.

Inflammation in the upper and lower airways of infants with acute bronchiolitis is dominated by an intense neutrophilia, and this is accompanied by release of products, such as human neutrophil elastase and metalloproteases which are likely to be driving much of the immunopathology observed in the primary infection (6-8). This neutrophilia is driven predominantly by high levels of IL-8 produced in response to RSV. A recent study assessing the relationship between IL-8 levels, neutrophils, and symptom severity during respiratory

Table 3. Geometric means (GM) and their $95 \%$ confidence intervals (Cl) of interleukins ratios

\begin{tabular}{lccc}
\hline & $\begin{array}{c}\text { RatiolL-17A: } \\
\text { IL-8GM (CI) }\end{array}$ & $\begin{array}{c}\text { RatiolL-17A: } \\
\text { IL-6GM (CI) }\end{array}$ & $\begin{array}{c}\text { RatiolL-6:IL-8 } \\
\text { GM (CI) }\end{array}$ \\
\hline I: infant control & $0.19(0.13-0.34)$ & $2.55(2.06-3.17)$ & $0.07(0.48-0.12)$ \\
$\begin{array}{l}\text { II: RSV-negative } \\
\text { infant }\end{array}$ & $0.05(0.02-0.13)$ & $1.99(1.20-3.29)$ & $0.02(0.01-0.05)$ \\
$\begin{array}{l}\text { III: RSV-positive } \\
\text { infant }\end{array}$ & $0.02(0.01-0.03)$ & $0.67(0.44-1.03)$ & $0.03(0.029-0.04)$ \\
$\begin{array}{l}\text { IV: RSV-positive } \\
\text { sibling }\end{array}$ & $0.12(0.04-0.2)$ & $2.81(2.23-3.39)$ & $0.04(0.01-0.12)$ \\
\hline
\end{tabular}

$P$ values refer to differences among the corresponding logarithmic values of the ratios in each group detected with ANOVA.

Statistically significant differences between groups, for each interleukin ratio: IL-17A:IL-8: RSV-positive infant-infant control $(P<0.001)$, RSV-positive infantRSV-positive sibling $(P=0.026)$, RSV-negative infant-infant control $(P=0.016)$ IL-17A:IL-6: RSV-positive infant-RSV-negative infant $(P=0.008)$, RSV-positive infant-infant control $(P<0.001)$, RSV-positive infant-RSV-positive sibling $(P=0.015)$

IL-6:IL-8: RSV-positive infant-infant control $(P=0.12)$. viral infections has confirmed our previous observations that neutrophil numbers correlate with IL-8 levels and that both IL-8 levels and neutrophil numbers correlate closely with symptom severity (29). The authors found this relationship to be consistent across a range of respiratory viruses. In our current study, we again found very high levels of IL- 8 in the upper respiratory tract of infants admitted with acute bronchiolitis. However, levels in their older symptomatic siblings experiencing a secondary infection were an order of magnitude lower. Given the close correlation between IL-8 levels, neutrophil numbers, and symptoms severity noted in the above studies, this finding is likely to be a key observation in explaining why the symptoms associated with secondary infections are generally much milder than the primary infection. It is also of note that levels of the proinflammatory cytokine IL-6 were also significantly lower in the secondary infection. These differences may simply be due to lower viral loads resulting in a less intense inflammatory response, but if this were the case, it would be anticipated that levels of all cytokines would be reduced proportionally during the secondary infection. This was not the case in that while levels of IL-17A, IL-21, and TNF $\alpha$ were all slightly lower in the older siblings as compared to their infant sibling, these differences were not significant, indicating a disproportion fall in both IL-8 and IL-6.

The data indicating greater levels of key proinflammatory cytokines in those infants with acute RSV bronchiolitis as compared to levels in non-RSV cases are consistent with the observed patterns of hospitalization in which the majority of cases of acute bronchiolitis are attributable to RSV infection and that those with RSV infection remain in hospital longer than the RSV-negative subjects. The epidemics of RSV infection occurring each winter appear to be attributable to a combination of poor herd immunity $(30,31)$ with infants being particularly severely affected due to relatively poor passively acquired immunity $(1,30-34)$, relatively small airways and a more intense inflammatory response (6).

As noted in the introduction, previous studies have identified IL-17 to be present in the airways of infants with RSV bronchiolitis (21-24). We had hypothesized that levels of IL-17 may have been higher during secondary infections. While this does not appear to be the case, IL-17 levels in both the primary and secondary infections being very similar the source of IL-17 may have differed between primary and secondary episodes. The elevated levels of IL-17 noted in the nasal secretions during primary infection are likely to be driven from a nonspecific innate response with neutrophils being one of the key contributors (35). During the secondary infection, production of IL-17 may be attributable to specific Th17 lymphocytes. The high levels of IL-6 observed in the airways of infants with a primary RSV infection would favor differentiation of a proportion of lymphocytes toward an IL-17-producing phenotype. A recent review (36) concluded that data from studies involving RSV-infected infants as well as animal models and in-vitro work with RSV-infected epithelium supported this suggestion. The potential role of 
TH17 cells in contributing to protection against repeated infection was also highlighted in a study which demonstrated that the RSV NS1 protein, which acts as an interferon antagonist, specifically suppresses proliferation and activation of both CD103+CD8+ cells and TH17 cells (37).

While there has been much interest in the role of IL-17 in the pathogenesis of chronic, autoimmune diseases such as rheumatoid arthritis, it also appears to have a beneficial role in acute bacterial infections such as those due to pneumococcal pneumonia $(13,14)$. Little is known about its role in respiratory viral infections. It is possible that it may contribute to improved clearance but IL-17 is also known to enhance IL-13 production, which in turn leads to increased mucus production and hence IL-17 is likely to be contributing to symptoms attributable to the excessive airways secretions characteristic of acute viral respiratory infections. The dynamics of IL-17 production and overall impact on symptoms and duration of illness of IL-17 production remain unclear. One study found that IL-17 levels in the noses of infants admitted with RSV bronchiolitis who were not ventilated were higher than in those who required mechanical ventilation (21). They also found that during the recovery phase IL-17 remained elevated while levels of other proinflammatory cytokines such as IL-8 and IL-6 fell (21). The authors speculated that IL-17 was contributing to both protection from more severe disease and resolution of the illness. In contrast, Bermejo-Martin et al. (22) found lower levels of IL-17 in nasal secretions of infants with RSV bronchiolitis at discharge as compared to admission. The same group also found IL-17 levels in nasal samples taken 1 year after an admission with RSV bronchiolitis were elevated compared with controls (23).

The relatively small subject groups particularly the older siblings with RSV infection is a potential limitation in this study though the magnitude of the changes in IL-8 and IL-6, together with the relatively narrow range of cytokines, make it unlikely that the results would be significantly different with greater numbers. No older age-matched controls for the older RSV-positive siblings were recruited. This would have provided information regarding the relative increase of cytokines during the acute illness from expected baseline, but this would not influence the conclusion about the different pattern of responses in the primary and secondary illnesses. Nasal samples rather than bronchoalveolar lavage samples were used for this study, as it would be impossible to obtain bronchoalveolar lavage samples from older siblings. This, however, does not influence the conclusions of this study as it has been long established that the cytokine and cellular profiles during acute RSV infections are very similar in the upper and lower airways $(6,38)$, leading to the routine use of nasal sampling for such studies.

In summary, this is the first study that compares inflammatory responses in primary and secondary RSV infections. Levels of the key proinflammatory cytokines, IL-6 and IL-8, appear to be significantly reduced in the secondary infection, while other potentially important cytokines were not significantly different.

\section{METHODS}

The study was approved by the Sheffield Research Ethics Committee. Written informed consent was obtained from the parents of all the subjects.

\section{Subjects}

Subjects were recruited during two consecutive winter RSV epidemics during the period November-March. Infants (patients less than a year of age) admitted to the Sheffield Children's Hospital with a clinical diagnosis of acute bronchiolitis were recruited. Infants who had a previous diagnosis of bronchiolitis were excluded. A single nasal sample was obtained as soon after admission as possible. The presence of RSV and other viruses was determined using PCR and immunofluorescence in all subjects. Primary RSV infection was therefore defined as children in their first year of life (and hence their first RSV season) presenting with a first bronchiolitic illness, who were RSV positive.

A nasal sample was also obtained from older preschool aged siblings of the RSV-positive cohort who had evidence of a significant upper respiratory tract infection. The samples underwent testing for RSV as well as for cytokine assays. Those who were RSV positive were assumed to be experiencing a secondary RSV infection and were included in the study. This assumption is based on the fact that it is well recognized that almost all children will have had RSV at least once previously by their second birthday (25-28).

Control infants were recruited from patients who were attending the hospital with nonacute, non respiratory problems. They were recruited outside of the RSV season and had no recent history of respiratory viral infections.

The subjects formed four groups (i) control infants without evidence of respiratory tract infections $(n=20)$; (ii) infants with acute bronchiolitis due to respiratory viruses other than RSV $(n=12)$; (iii) infants with RSV-positive acute bronchiolitis $(n=39)$; and (iv) older preschool siblings of group one patients with upper respiratory tract symptoms who were also RSV positive $(n=7)$.

\section{Nasal Swab Sampling}

Sampling was performed by a single investigator and involved introducing a soft flocked nasal swab (COPAN, Brescia, Italy) a fixed distance of $2 \mathrm{~cm}$ into a nostril and rotating it once to soak up secretions within the nostril as previously described (39). The tip of the swab was put into a plastic vial containing $0.5 \mathrm{ml}$ of UTM-RT virus transport medium (COPAN) and the applicator stick broken off.

The cotton bud was subsequently rotated in the plastic vial within an isolation hood and the vials then centrifuged at $1,200 \mathrm{rpm}$ for $10 \mathrm{~min}$. The swab was removed, and the vial containing the media and nasal secretions was stored at $-70^{\circ} \mathrm{C}$.

\section{Measurement of Cytokines and Chemokines by Cytokine Bead Array}

All samples from the study were defrosted and analyzed as a single batch. Levels of IL-6, IL-8, IL-17 $\alpha$, IL-21, and TNF were measured using standard commercially available Cytokine Bead Array kits and a FACSArray Flow Cytometer (Becton Dickinson, Erembodegem, Belgium). Assays were performed in the Flow Cytometry Core Facility in the School of Medicine and Biomedical Sciences, University of Sheffield, and standardized using appropriate controls.

\section{Statistical Analysis}

The distributions of cytokines values and their ratios were highly positively skewed and so we summarized our data using their geometric means and their corresponding 95\% confidence intervals. Furthermore, in order to perform a valid analysis, we proceeded in logarithmic transformation of the data using the natural logarithm with base e. The log-transformed data followed the normal distribution and so we were able to use parametric tests for our analysis. The order of a data set is preserved after log-transformation, and the $P$ values computed after transformation applies to original data (40).

We used ANOVA for comparisons between groups, and Bonferoni post hoc test to identify the pairs of groups where statistically significant differences existed. We also applied a multiple regression model using IL- 8 as the response variable and IL-6, IL-17A, IL-21, and TNF as explanatory variables taking into account the classification by groups.

Volume 79 | Number 6 | June $2016 \quad$ Pediatric RESEARCH 


\section{STATEMENT OF FINANCIAL SUPPORT}

Funding for this study was provided by the Sheffield Children's Hospital Charity Research Fund.

Disclosure: There are no conflicts of interest.

\section{REFERENCES}

1. Everard ML. Textbook of Paediatric Respiratory Medicine. 2nd edn. St Louis: Mosby, 2009:491-500.

2. Hall CB, Weinberg GA, Blumkin AK, et al. Respiratory syncytial virusassociated hospitalizations among children less than 24 months of age. Pediatrics 2013;132:e341-8.

3. Centers for Disease Control and Prevention (CDC). Respiratory syncytial virus activity - United States, July 2008-December 2009. MMWR Morb MortalWkly Rep 2010;30-3.

4. Zhou H, Thompson WW, Viboud CG, et al. Hospitalizations associated with influenza and respiratory syncytial virus in the United States, 1993-2008. Clin Infect Dis 2012;54:1427-36.

5. Nair H, Nokes DJ, Gessner BD, et al. Global burden of acute lower respiratory infections due to respiratory syncytial virus in young children: a systematic review and meta-analysis. Lancet 2010;375:1545-55.

6. Everard ML, Swarbrick A, Wrightham M, et al. Analysis of cells obtained by bronchial lavage of infants with respiratory syncytial virus infection. Arch Dis Child 1994;71:428-32.

7. Smith PK, Wang SZ, Dowling KD, Forsyth KD. Leucocyte populations in respiratory syncytial virus-induced bronchiolitis. J Paediatr Child Health 2001;37:146-51.

8. Abu-Harb M, Bell F, Finn A, et al. IL-8 and neutrophil elastaselevels in the respiratory tract of infants with RSV bronchiolitis. Eur Respir J 1999;14:139-43.

9. Evans GS, Jones A, Qui JM et al. Neutrophil survival is prolonged in the airways of healthy infants and infants with RSV bronchiolitis. Eur Respir J 2002;20:651-7.

10. Viuff B, Tjørnehøj K, Larsen LE, et al. Replication and clearance of respiratory syncytial virus: apoptosis is an important pathway of virus clearance after experimental infection with bovine respiratory syncytial virus. Am J Pathol 2002;161:2195-207.

11. Bataki EL, Evans GS, Everard ML. Respiratory syncytial virus and neutrophil activation. Clin Exp Immunol 2005;140:470-7.

12. Coleman CM, Plant K, Newton S, Hobson L, Whyte MK, Everard ML. The anti-apoptotic effect of respiratory syncytial virus on human peripheral blood neutrophils is mediated by a monocyte derived soluble factor. Open Virol J 2011;5:114-23.

13. Lu YJ, Gross J, Bogaert D, et al. Interleukin-17A mediates acquired immunity to pneumococcal colonization. PLoS Pathog 2008;4:e1000159.

14. Zhang Z, Clarke TB, Weiser JN. Cellular effectors mediating Th17dependent clearance of pneumococcal colonization in mice. J Clin Invest 2009;119:1899-909.

15. Moffitt KL, Gierahn TM, Lu YJ, et al. T(H)17-based vaccine design for prevention of Streptococcus pneumoniae colonization. Cell Host Microbe 2011;9:158-65.

16. Kimura A, Naka T, Kishimoto T. IL-6-dependent and -independent pathways in the development of interleukin 17-producing T helper cells. Proc Natl Acad Sci USA 2007;104:12099-104.

17. Martinez GJ, Nurieva RI, Yang XO, Dong C. Regulation and function of proinflammatory TH17 cells. Ann NY Acad Sci 2008;1143:188-211.

18. Hornsleth A, Klug B, Nir M, et al. Severity of respiratory syncytial virus disease related to type and genotype of virus and to cytokine values in nasopharyngeal secretions. Pediatr Infect Dis J 1998;17:1114-21.

19. McNamara PS, Flanagan BF, Selby AM, Hart CA, Smyth RL. Pro- and antiinflammatory responses in respiratory syncytial virus bronchiolitis. Eur Respir J 2004;23:106-12.
20. Stoppelenburg AJ, de Roock S, Hennus MP, Bont L, Boes M. Elevated Th17 response in infants undergoing respiratory viral infection. Am J Pathol 2014;184:1274-9.

21. Faber TE, Groen H, Welfing M, Jansen KJ, Bont LJ. Specific increase in local IL-17 production during recovery from primary RSV bronchiolitis. J Med Virol 2012;84:1084-8.

22. Bermejo-Martin JF, Garcia-Arevalo MC, Alonso A, et al. Persistence of proinflammatory response after severe respiratory syncytial virus disease in children. J Allergy Clin Immunol 2007;119:1547-50.

23. Pino M, Kelvin DJ, Bermejo-Martin JF, et al. Nasopharyngeal aspirate cytokine levels $1 \mathrm{yr}$ after severe respiratory syncytial virus infection. Pediatr Allergy Immunol 2009;20:791-5.

24. Larrañaga CL, Ampuero SL, Luchsinger VF, et al. Impaired immune response in severe human lower tract respiratory infection by respiratory syncytial virus. Pediatr Infect Dis J 2009;28:867-73.

25. Hall CB, Geiman JM, Biggar R, Kotok DI, Hogan PM, Douglas GR Jr. Respiratory syncytial virus infections within families. N Engl J Med 1976;294:414-9.

26. Glezen WP, Taber LH, Frank AL, Kasel JA. Risk of primary infection and reinfection with respiratory syncytial virus. Am J Dis Child 1986;140:543-6.

27. Henderson FW, Collier AM, Clyde WA Jr, Denny FW. Respiratorysyncytial-virus infections, reinfections and immunity. A prospective, longitudinal study in young children. N Engl J Med 1979;300:530-4.

28. Hall CB. The burgeoning burden of respiratory syncytial virus among children. Infect Disord Drug Targets 2012;12:92-7.

29. Henriquez KM, Hayney MS, Xie Y, Zhang Z, Barrett B. Association of interleukin-8 and neutrophils with nasal symptom severity during acute respiratory infection. J Med Virol 2015;87:330-7.

30. Everard ML, Milner AD. The respiratory syncitial virus and its role in acute bronchiolitis. Eur J Pediatr 1992;151:638-51.

31. Kinyanjui TM, House TA, Kiti MC, Cane PA, Nokes DJ, Medley GF. Vaccine induced herd immunity for control of respiratory syncytial virus disease in a low-income country setting. PLoS One 2015;10:e0138018.

32. Ohuma EO, Okiro EA, Ochola $\mathrm{R}$, et al. The natural history of respiratory syncytial virus in a birth cohort: the influence of age and previous infection on reinfection and disease. Am J Epidemiol 2012;176:794-802.

33. Sande CJ, Mutunga MN, Okiro EA, Medley GF, Cane PA, Nokes DJ. Kinetics of the neutralizing antibody response to respiratory syncytial virus infections in a birth cohort. J Med Virol 2013;85:2020-5.

34. Modjarrad K, Giersing B, Kaslow DC, Smith PG, Moorthy VS; WHO RSV Vaccine Consultation Expert Group. WHO consultation on respiratory syncytial virus vaccine development report from a World Health Organization meeting held on 23-24 March 2015. Vaccine 2016;34:190-7.

35. Cua DJ, Tato CM. Innate IL-17-producing cells: the sentinels of the immune system. Nat Rev Immunol 2010;10:479-89.

36. Mangodt TC, Van Herck MA, Nullens S, et al. The role of Th17 and Treg responses in the pathogenesis of RSV infection. Pediatr Res 2015;78:483-91.

37. Munir S, Hillyer P, Le Nouën C, et al. Respiratory syncytial virus interferon antagonist NS1 protein suppresses and skews the human T lymphocyte response. PLoS Pathog 2011;7:e1001336.

38. Everard ML, Fox G, Walls AF, et al. Tryptase and IgE concentrations in the respiratory tract of infants with acute bronchiolitis. Arch Dis Child 1995;72:64-9.

39. Bhatt JM, White C, Iqbal SM, Ritson S, Evans GS, Everard ML. Evaluation of nasal swabs for monitoring inflammation in RSV bronchiolitis. ERJ 2000;16:Suppl 31:563S.

40. Olivier J, Johnson WD, Marshall GD. The logarithmic transformation and the geometric mean in reporting experimental $\mathrm{IgE}$ results: what are they and when and why to use them? Ann Allergy Asthma Immunol 2008;100:333-7. 